\title{
A emergência dos smart speakers: desafios e oportunidades para o rádio no contexto do big data ${ }^{1}$
}

\section{The emergence of smart speakers: challenges and opportunities for radio broadcasting in the context of the big data}

\author{
Marcelo Kischinhevsky*, Debora Cristina Lopez**
}

*Universidade Federal do Rio de Janeiro, Brasil

**Universidade Federal de Ouro Preto, Brasil

Resumo

\begin{abstract}
O presente artigo, de caráter exploratório, analisa a emergência dos smart speakers e a reintermediação que o dispositivo opera no mercado de mídia sonora, num contexto de crescente investimento corporativo em big data. No percurso, são elencados os desafios no horizonte e as oportunidades para as tradicionais emissoras de rádio, que precisarão se tornar parceiras de gigantes de tecnologia para assegurar um lugar de destaque no novo ecossistema midiático, em que hábitos de escuta antes solidamente estabelecidos são redesenhados. Além de pesquisa bibliográfica e documental, foram realizadas entrevistas com gestores de duas emissoras brasileiras que vêm investindo na distribuição de conteúdos radiofônicos por meio de assistentes de voz, permitindo-nos refletir sobre o papel que estes novos intermediários podem vir a desempenhar no mercado de mídia sonora.
\end{abstract}

Palavras-chave: Comunicação; Rádio; Smart Speakers; Big Data.

\section{Abstract}

This exploratory article analyzes the emergence of smart speakers and the re-intermediacy carried out by this device in audio media market, in a context of growing corporate investment in big data. In this theoretical path, we summarize are challenges on the horizon and the opportunities for traditional radio broadcasters, who will be compelled to seek partnerships with technology giants to ensure a prominent place in the new media ecosystem, where previously established listening habits are redesigned. In addition to bibliographic and documental research, interviews were conducted with managers of two Brazilian broadcasters who have been investing in the distribution of radio content through voice assistants, allowing us to reflect on the role these new intermediaries may play on audio media market.

Keywords: Communication; Radio; Smart Speakers; Big Data.

Submitted: $12^{\text {th }}$ November 2018

Accepted: $18^{\text {th }}$ March 2019

\section{How to quote this article:}

Kischinhevsky, M., Lopez, D.C. (2019). A emergência dos smart speakers: desafios e oportunidades para o rádio no contexto do big data. Observatorio, 13(2), 125-141.

\footnotetext{
${ }^{1}$ Versão revista e ampliada de trabalho apresentado no Grupo de Pesquisa Rádio e Mídia Sonora, durante o XVIII Encontro dos Grupos de Pesquisas em Comunicação, evento componente do $41^{\circ}$ Congresso Brasileiro de Ciências da Comunicação, realizado em setembro de 2018, em Joinville, SC, Brasil. Este artigo apresenta resultados parciais do projeto de pesquisa "Conhecer o ouvinte-internauta: Um estudo sobre o perfil da audiência de rádio no cenário de convergência", financiado pelos editais PROPP Auxílio Financeiro ao Pesquisador da UFOP, Chamada CNPq/ MCTI No 25/2015 - Ciências Humanas, Sociais e Sociais Aplicadas e Edital FAPEMIG 01/2015 - Demanda Universal e FAPEMIG - Bolsa Pesquisador Visitante.
} 


\section{"Alexa, ligue o rádio"}

Assistentes de voz como Siri, da Apple, se popularizaram ao longo dos anos 2010, embora ainda fossem vistos com desconfiança por muitos usuários de telefones móveis, devido aos anedóticos erros de interpretação da inteligência artificial em relação aos comandos emitidos através da fala humana ${ }^{2}$. Nesse contexto, o mercado de tecnologia não deu grande atenção ao lançamento do Amazon Echo, em 2015, um pequeno alto-falante conectado à internet e desenhado para atender a comandos de voz complexos. Mas Alexa, a assistente de voz da Amazon, superou todas as expectativas e tornou-se rapidamente uma personagem popular, ajudando nas mais diversas tarefas cotidianas, desde o acesso a conteúdos midiáticos até a gestão de eletrodomésticos, como aparelhos de ar-condicionado/calefação, passando pela elaboração de listas de compras, acionamento de luzes, funções de alarme e despertador e atividades inusitadas como contar piadas e tirar dúvidas de conhecimentos gerais. Por se tratar de um sistema de inteligência artificial de voz, os smart speakers avançam em seu aprendizado de acordo com o uso. Noda $(2017$, p. 2) lembra que ao contrário das unidades de voz instaladas em smartphones, que seguem estritamente sua programação prévia, esses dispositivos continuam expandindo sua inteligência artificial aprendendo comportamento humano, reconhecimento de fala e habilidades de conversação diariamente.

A pesquisa sobre smart speakers também está em seus primeiros passos. Segundo Smith (2017), uma busca pelos termos "Google Home" e "Amazon Echo" no Scopus, em outubro de 2017, levou a oito e 16 resultados, respectivamente. Em ambos casos, as pesquisas de ciências da computação respondiam por $75 \%$ dos estudos, enquanto os estudos de ciências sociais ficavam com 25\% e 18,8\%. O autor destaca, entre as produções, a observação das interações entre a audiência e o dispositivo, em um processo de personificação da inteligência artificial similar ao ocorrido com o rádio em seus tempos de maior audiência, em meados do século $X X$.

Refizemos a busca no Scopus e constatamos que o interesse pelos assistentes de voz é crescente: no início de março de 2019, o número de ocorrências da expressão "Google Home" chegava a 66, das quais 55 (equivalentes a 83,3\%) se inseriam na área de ciências da computação e apenas sete (10,6\%) se relacionavam às ciências sociais. Já as citações a "Amazon Echo" totalizavam 78, das quais 66 (84,6\%) da área de ciências da computação e seis $(7,7 \%)$ de ciências sociais - mesmo número de artigos das áreas de ciências da saúde e de decisão.

Segundo dados da pesquisa The Infinite Dial, da Edison Research e da Triton (2018), ao fim de 2017, nada menos que $18 \%$ dos norte-americanos com 12 anos de idade ou mais - aproximadamente 51 milhões de pessoas - já possuíam smart speakers. Um terço deles tinha dois ou mais aparelhos em casa. Um ano antes, o percentual de americanos com o gadget era de 7\%, ou seja, o crescimento de 2016 para 2017 foi de mais de $150 \%$. O estudo destaca que a adoção dos smart speakers está ocorrendo em ritmo 40 vezes mais acelerado que o registrado pelos smartphones no mesmo período após o lançamento. Uma explicação

\footnotetext{
${ }^{2}$ As primeiras iniciativas de inteligência artificial e interação por fala natural datam de muito antes do sucesso comercial dos smart speakers. Smith (2017) cita a experiência de Joseph Weisenbaum no MIT, que já nos anos 1960 desenvolveu o programa ELIZA, que utilizava linguagem natural para interagir com os usuários através de uma tela simples. Eles eram instruídos, no uso, a "falar" com o sistema, como falariam com um terapeuta. ELIZA simula, em sua interface, a fala, o diálogo. E para Weisenbaum esta estratégia levou à antropomorfização do sistema, humanizado pelos usuários nas interações analisadas e com grande capacidade de acionamento de emoções.
} 
possível para a grande aceitação destes dispositivos é o custo: enquanto os smartphones de última geração podem custar mais de US\$ 1 mil, os alto-falantes inteligentes têm preços a partir de US\$ 20.

Pioneira no filão, a Amazon tinha, em 2017, aparelhos em 83\% dos lares equipados com smart speakers nos Estados Unidos. Em segundo lugar, bem atrás, vinha a Google, com seu Google Home em 28\% dos domicílios norte-americanos - os números superam $100 \%$ porque, como mencionado acima, parte dos entrevistados tinha mais de um aparelho, às vezes de marcas diferentes. 0 então recém-lançado Apple HomePod, que também conta com a assistente de voz Siri, ainda não aparecia nos dados. Outros atores importantes da indústria eletroeletrônica, como Samsung, Sony e JBL, já anunciaram projetos para o segmento. Em fevereiro de 2019, a Samsung anunciou a data de lançamento do seu Galaxy Home. 0 principal diferencial é a promessa de ser o único smart speaker a direcionar o som para o usuário ${ }^{3}$ (Galaxy Home, 2019).

A chegada dos smart speakers ocorre numa fase de desafios, tanto para as indústrias radiofônica quanto fonográfica, que moldaram, ao longo do século XX, a maior parte da comunicação sonora. Nos últimos 20 anos, o mercado da mídia sonora foi completamente reconfigurado, com a digitalização de processos. Depois de uma década de desorganização, com o avanço dos serviços de compartilhamento de arquivos de áudio e o declínio dos suportes físicos, a indústria fonográfica reagiu e começou a impor novos padrões. Primeiro, foram os downloads pagos e os ringtones para telefonia móvel, que ajudaram as companhias musicais a finalmente faturar no segmento digital. Nos últimos quatro anos, foi a vez da ascensão dos serviços de streaming (De Marchi, 2016, Kischinhevsky, Vicente e De Marchi, 2015), que vêm acirrando um processo de consolidação na mídia sonora em nível internacional (Vicente, Kischinhevsky e De Marchi, 2018, Kischinhevsky e De Marchi, 2016). O rádio, concorrendo pela atenção da audiência com a internet, tornouse um meio expandido, transbordando das ondas hertzianas para diversos suportes e dispositivos (Kischinhevsky, 2016). Agora, todos os segmentos da indústria da mídia sonora se voltam para os novos dispositivos acionados por voz, que têm potencial para assumir rapidamente o papel de poderosos intermediários no mercado de áudio.

Ainda segundo a pesquisa The Infinite Dial, a expansão do número de smart speakers coincide com o acelerado declínio do rádio analógico nos Estados Unidos. O percentual de domicílios com aparelhos de rádio recuou para 71\% em 2017, e 5\% dos entrevistados têm alto-falantes inteligentes em casa, mas não possuem mais receptor AM/FM. Os autores do estudo advertem que "marcas e anunciantes precisam rapidamente desenvolver uma estratégia de áudio que leve em conta essa dramática mudança" (tradução nossa) $)^{4}$.

Há quem receba com otimismo o novo dispositivo. O pesquisador espanhol Luis Miguel Pedrero Esteban destaca que, pela primeira vez em quase um século, a inovação tecnológica oferece ao rádio "um aliado e não um obstáculo" (2018). Isso porque, diferentemente da TV e da internet, que roubaram as atenções da audiência, os smart speakers são acionados primordialmente por voz. Este fato, em princípio trivial, na prática faz toda a diferença, ao recuperar a relevância da comunicação sonora num ambiente cada vez mais ocupado por dispositivos que se desenvolveram em torno de telas e que exigem uma série de habilidades táteis - abrir e fechar janelas e apps com rápidos gestos utilizando um ou mais dedos, por exemplo.

\footnotetext{
${ }^{3}$ Há aqui uma controvérsia, já que a Apple também afirma que o HomePod realiza esse direcionamento, o que é questionado pelos usuários.

${ }^{4}$ No original: "Brands and advertisers need to quickly develop an audio strategy that accouts for this dramatic change".
} 
O debate também vai além do que ele possibilita, estendendo-se para como os assistentes de voz têm se colocado na ecologia dos meios, disputando um espaço na curva de inovação da comunicação (ROGERS, 1983). Park et al (2018) olham para o fenômeno dos smart speakers a partir do processo de adoção da plataforma e consideram, para isso, o valor, os benefícios e os riscos percebidos; as variáveis relacionadas ao produto, como a funcionalidade, o design, a marca, o preço; as variáveis relacionadas à plataforma, como a percepção da disponibilidade, do tamanho da rede, da complementaridade (que é associada ao risco percebido, como nas questões de privacidade, por exemplo). No modelo de análise proposto pelos autores, eles buscam compreender as intenções de adoção da plataforma a partir da triangulação entre principalmente entre os benefícios e riscos percebidos, que definem a percepção do valor dos smart speakers para os usuários. A partir de uma pesquisa empírica que envolveu 315 indivíduos consumidores de assistentes de voz na Coréia do Sul, eles concluem que os benefícios percebidos têm efeito maior do que os riscos na configuração do valor das plataformas. Ainda segundo os autores, questões sobre privacidade, muito presentes no debate sobre o uso de assistentes de voz, foram detectadas como os riscos principais da adoção. $O$ estudo revela ainda que os atributos relacionados à plataforma têm papel central na intenção de adotar um smart speaker, já que a disponibilidade, o tamanho da rede e a complementaridade são associados a um marketing agressivo que traz à tona mais usos para o dispositivo - que vão além da escuta de programas como um emulador de rádio, potencializando o diálogo com a inteligência artificial e o desenvolvimento e exploração de novas habilidades. Este foco nos fazeres dos smart speakers e em sua aplicabilidade ao cotidiano dos usuários os está convertendo de dispositivos miniaturizados da casa em plataformas integradas geradoras de dados e de novas práticas de consumo de conteúdo sonoro.

Mas os smart speakers, vendidos no varejo norte-americano aos milhões de unidades, ampliam também o debate sobre os riscos de oligopolização da comunicação e da cultura. O novo dispositivo surge num contexto em que grandes corporações exploram as potencialidades do chamado big data, alterando a balança na relação de forças entre os diversos atores da mídia e redesenhando hábitos de escuta antes solidamente estabelecidos. Esta perspectiva, discutida a seguir, é a base do presente estudo. Através de uma pesquisa exploratória nos ambientes da Amazon e da Google, incluindo revisão bibliográfica e pesquisa documental, foi realizado um levantamento da presença de conteúdos informativos em áudio no mercado brasileiro, com prioridade para emissoras de rádio. Em um segundo momento, foram realizadas entrevistas semiestruturadas com responsáveis pela implementação destes serviços no Sistema Globo de Rádio, do Rio de Janeiro, e na Rede Gazeta, de Vitória, duas das mais importantes redes de rádio informativo no país. As entrevistas semiestruturadas permitem uma compreensão mais clara de como o mercado de um país periférico, em que as novas tecnologias têm lenta adoção devido à profunda desigualdade no acesso a bens e serviços, tem se movimentado para organizar sua participação neste novo espaço de produção e circulação de conteúdo sonoro.

\section{Mídia sonora em tempos de big data}

Com a informatização acelerada nos mais diversos campos da atividade humana, a partir dos anos 1980, dados passaram a estar em toda parte. Na última década, seu uso é crescente em áreas como marketing, administração, comércio eletrônico, inteligência artificial e gestão pública. 
Quando entramos no Facebook e curtimos postagens de algumas pessoas, e não de outras, a inteligência artificial que rege o sistema entende que devemos ver mais, em nossas timelines, daquelas pessoas com quem interagimos. Se clicamos num anúncio sobre televisores, imediatamente toda a navegação na internet passa a ser invadida por ofertas de aparelhos de TV.

Quando vamos a um supermercado, câmeras permitem o mapeamento de áreas em que vamos de forma recorrente, e essa informação pode ser usada para nos vender produtos específicos. Não é coincidência que, perto do caixa, sejam sempre posicionadas prateleiras repletas de balas, doces, lâminas de barbear e outros itens que compramos por impulso, muitas vezes sem comparar preços.

Quando usamos o cartão de crédito, geramos um enorme volume de informações sobre hábitos de consumo. A funcionalidade de localização do telefone móvel permite que os deslocamentos pela cidade sejam mapeados por empresas que têm acesso a estas informações, muitas vezes terceirizando-as para parceiros comerciais. Somos invadidos por pedidos de avaliação de lugares onde estamos ou pelos quais apenas passamos perto - bares, restaurantes, hotéis, lojas, museus.

Mais que isso: numa lógica amplamente disseminada de crowdsourcing, em serviços tão distintos quanto a loja virtual da Amazon e o Trip Advisor, baseamo-nos nas avaliações de estranhos para decidir o que comprar, onde vamos nos hospedar e o que devemos pedir para o jantar. Quando navegamos pelo menu do Netflix, o sistema monitora os filmes e séries a que assistimos para nos oferecer novas atrações e gera dados até a partir do tempo que gastamos lendo as informações sobre um determinado programa.

O big data é um novo ambiente no qual estamos imersos, o que coloca uma série de desafios à pesquisa em comunicação. Uma das principais causas da reconfiguração do jornalismo, visto hoje como uma atividade pós-industrial por Anderson, Bell e Shirky (2012), é justamente o colapso de um modelo de negócios baseado na publicidade massiva. A publicidade cada vez mais migra para plataformas de comércio eletrônico e portais de entretenimento. Há apenas 20 anos, a imprensa e os meios eletrônicos tinham a preponderância como espaços privilegiados para a veiculação de anúncios. Com a internet, no entanto, a publicidade abandona o conteúdo jornalístico que lhe conferia alguma respeitabilidade e abraça a instantaneidade do mundo digital, com todas as suas possibilidades de faturamento num mercado globalmente segmentado. Não se discutirá aqui o big data a partir de chaves conceituais como vigilância ${ }^{5}$, mas o fato é que, na medida em que inteligências artificiais cada vez mais sofisticadas nos oferecem produtos e serviços a partir de nossas escolhas prévias, enfrentamos uma limitação inédita. A fragmentação das audiências traz uma série de riscos à democracia representativa, acirrando polarizações alimentadas por conteúdos caça-cliques em mídias sociais, muitas vezes sem qualquer ancoragem na realidade.

Os pesquisadores canadenses Amir Gandomi e Murtaza Haider (2015) mostram que a expressão big data nasce nos anos 1990 no mercado de tecnologia da informação e ganha popularidade a partir de 2011, com o uso em campanhas de marketing da IBM e outras empresas. Os autores fazem uma revisão bibliográfica

\footnotetext{
${ }^{5}$ Em maio de 2018, a imprensa internacional noticiou um caso insólito ocorrido nos EUA: um casal de Portland teve uma conversa gravada por seu Amazon Echo, que enviou o arquivo de áudio a um colega de trabalho do marido. Técnicos acreditam que Alexa "despertou" ao ser mencionada na conversa e acabou interpretando o diálogo como um comando de gravação e envio da mensagem (LEE, 2018). O fato levantou discussões sobre a privacidade dos usuários de smart speakers, a exemplo do que já havia ocorrido há alguns anos com as possibilidades de que câmeras de smart TVs fossem hackeadas. De fato, as empresas armazenam conversas, sob alegação de que estas são decisivas para o aprendizado da inteligência artificial. Mas, embora os termos de uso as impeçam de comercializar seu teor, é evidente que a interação humana ao alcance dos microfones dos smart speakers fornece uma série de dados que potencialmente podem ser rentabilizados, por meio da oferta de produtos e serviços segmentados de acordo com perfis cada vez mais individualizados.
} 
do conceito, recuperando a definição de Doug Laney, para quem a gestão de dados tem três dimensõeschave, os chamados 3 Vs: Volume, Velocidade e Variedade.

Quanto ao volume, vivemos hoje um mundo em que a capacidade de armazenamento dos dispositivos cresceu bem além das possibilidades de esgotamento pela maioria das pessoas físicas. Um computador comum, com HD de 1 terabyte (TB), comporta conteúdo equivalente a 1.500 CDs ou 220 DVDs, suficiente para armazenar 16 milhões de fotos. Em 2016, entramos na era dos zettabytes: segundo levantamento da Cisco Systems (2017), naquele ano o total de tráfego de dados nas redes digitais chegou a inéditos 1,2 ZB, o equivalente a 1,3 bilhão de terabytes. Redes dedicadas à distribuição de conteúdo online (Content Delivery Networks) já respondiam por $52 \%$ do tráfego total da internet, e a expectativa era de que esse percentual atingirá 71\% em 2021.

Velocidade dispensa maiores explicações. Com a expansão do mercado de smartphones, a geração de dados móveis, como localização geoespacial, informações pessoais e padrões de compras, disparou. Ainda de acordo com a Cisco, a média global da velocidade de banda larga - apesar das persistentes desigualdades regionais - atingiu 27,5 megabits por segundo (MBps) em 2016, e a expectativa é de que quase dobre até 2021, chegando a 53Mbps.

Variedade, por sua vez, diz respeito ao tipo de dados gerados, que podem ser estruturados, semiestruturados ou desestruturados. Dados estruturados, que representavam no início da década cerca de $5 \%$ do total, abrangem planilhas, repositórios indexados, documentos catalogados por categorias que permitem variadas formas de busca. Ganham importância com as legislações de transparência, sobretudo em relação às contas públicas. Os semiestruturados, por sua vez, são aqueles que possibilitam marcações específicas e limitadas, como páginas em XML. Já os desestruturados compreendem textos, imagens, áudios, vídeos.

Negócios dos mais diversos portes estão hoje minerando dados gerados, por exemplo, pela circulação de pessoas em espaços públicos ou privados, através de softwares de reconhecimento facial e sistemas que possibilitam a otimização de vendas personalizadas.

Fronteiras importantes estão nas técnicas de Question Answering (QA), usadas em sistemas de assistentes de voz e atendentes virtuais - as plataformas de Interactive Voice Response -, nas análises de sentimentos, sistemas programados de valências que identificam potenciais danos a marcas nas mídias sociais, e na análise de áudio, que comporta longas interações em call centers, permitindo estabelecer padrões e evitar explosões de fúria por parte do consumidor que, não raro, pena para solucionar qualquer problema via teleatendimento.

Chama a atenção o fato de que meios de comunicação, tanto grandes quanto pequenos, ignoram solenemente o potencial do big data. Emissoras de rádio insistem em fórmulas desgastadas, como spots de 30 segundos e anúncios de pop-up e publicidade na forma de banners em seus sites. Enquanto isso, novos atores da internet, como blogs e serviços que operam na lógica do jornalismo computacional (Coddington, 2015, Lewis, 2015), muitas vezes permitem login por intermédio de redes sociais on-line, o que abre portas para um manancial de dados.

A pesquisadora americana Lady Dhyana Ziegler destaca que empresas de mídia capazes de integrar tecnologia à programação, ao marketing e a decisões de gestão vêm obtendo importante vantagem competitiva através de seus sistemas de distribuição e plataformas, possibilitando o uso de big data para aferir o sucesso de seus produtos. Ela aponta, no entanto, que o rádio tem sido muito mais lento para mudar 
seu modelo de negócios. Para a autora, a capacidade de utilizar recursos digitais para gerar big data e acompanha-lo em tempo real será decisiva para o rádio se manter relevante e competitivo no novo ambiente midiático.

No mundo de hoje, as medições de audiência residem na análise de big data. 0 rádio precisa saber que tipos de dispositivos seus ouvintes usam e precisa saber que conteúdos midiáticos a audiência consome, por exemplo, notícias e música. Eles precisam ser capazes de quantificar dados de mídia social e analíticos de música. Conjugado a isso, audiências também têm interesse em imersão e/ou conteúdo de realidade virtual.

[...] O rádio pode ser um grande jogador no mundo do big data através de dispositivos móveis e carros inteligentes. (Ziegler, 2016, p. 184-185) ${ }^{6}$

Como plataforma interativa, os smart speakers oferecem amplo espectro de possibilidades de mineração de dados, favorecendo conglomerados de tecnologia da informação e acirrando um movimento de declínio da mídia tradicional, cada vez mais relegada a um papel de coadjuvante. A pesquisadora Sofia Martins destaca que o acionamento de serviços nos assistentes de voz permite a coleta de informações sobre o usuário em um duplo modo: a) através dos dados gerados por suas práticas de consumo de bens culturais, de compras e buscas; b) através das gravações das conversas em si. "A meta de um assistente virtual é conhecer seu dono de forma íntima para poder lhe ajudar da melhor forma possível. Por isso, essas [...] companhias armazenam suas palavras indefinidamente em sua conta pessoal" (Martins, 2017). Há alguns exemplos, como o do já mencionado casal norte-americano que teve uma conversa privada gravada e enviada a um colega de trabalho e o do hacker inglês Mark Banes, que provou ser possível transformar um Amazon Echo em uma escuta que não deixa rastros físicos e pode ser mantida gravando indefinidamente (Greenberg, 2017).

A integração destes dispositivos à internet das coisas tem revelado potenciais de coleta de dados, como o caso da utilização pela CIA das smart TVs da Samsung. Martins, no entanto, lembra que as empresas fabricantes dos smart speakers têm trabalhado em dispositivos de segurança, como a codificação das gravações e a suposta desconexão, no caso da Apple, entre as gravações e os usuários depois de seis meses. Desta forma, observa-se um investimento na coleta de dados de maior dimensão, não necessariamente associados ao usuário em si, mas que revelam práticas amplas de consumo e a eficiência de estratégias de comunicação estabelecidas através dos dispositivos.

Bentley et al. (2018), embora não trabalhem especificamente com big data, analisam alguns dos rastros digitais deixados pelos usuários de smart speakers para tentar compreender o fenômeno de maneira mais ampla. Com a perspectiva de métodos digitais aplicados ao rádio (Lopez, Freire, 2018), os autores analisaram 65.499 interações realizadas durante 110 dias em 88 domicílios com assistentes de voz. 0 objetivo era compreender como esse uso é realizado e a relação dos sujeitos com os comandos de voz em si, partindo da caracterização básica deste uso (como a configuração das famílias nas casas, a quantidade de pessoas que usava a plataforma) chegando até uma ordenação do uso em si (quais comandos, com qual

\footnotetext{
${ }^{6}$ No original: "In today's world, audience measurements reside in big data analysis. Radio must know what types of devices members of their audience use and must know the media content audiences consume, e.g., news and music. They must be able to quantify social media data and music analytics. Coupled with that, audiences also have interest in immersion and/or virtual reality content.

[...] Radio can be a major player in a big data world through mobile devices and smart cars" (ZIEGLER, 2016, p. 184185).
} 
frequência, em que grupo de ações os comandos predominavam). Com isso, entre outras questões, conseguiram desenhar um mapa dos comandos mais relevantes em cada hora do dia, que revela música, informação e automação da casa como os três conteúdos mais acessados e acessados de maneira mais uniforme no decorrer do dia na amostra analisada.

Os termos mais utilizados por categoria delimitam um caráter assertivo na relação com o dispositivo, principalmente em relação à música, automação, alarme e lista de compras. Já as habilidades que envolvem perguntas, como as conversas gerais e o tempo e a temperatura são mais dialogais e com caráter eminentemente interativo, sendo menos assertivo e mais longos na duração do comando. Os autores classificam os usuários em quatro níveis de intensidade: leves, médios, exploradores e super usuários. Os três primeiros apresentam uma diferença média de dois pontos em relação ao número de comandos que realizam diariamente, enquanto o dos super usuários é quatro vezes maior que o dos exploradores. Entre as principais conclusões do trabalho está a intensificação do uso dos assistentes de voz em dispositivos como Google Home em relação à utilização identificada anteriormente em dispositivos móveis, gerada principalmente pelas habilidades de automação e a integração a sistemas inteligentes.

\section{Reintermediação da mídia sonora}

A pesquisa The Smart Audio Report, divulgada pela NPR e pela Edison Research no período de outonoinverno de 2017, mostra que os alto-falantes inteligentes parecem estar assumindo um papel dominante na indústria. Perguntados sobre o modo mais frequente de ouvirem áudio, nada menos que $18 \%$ dos entrevistados citaram os smart speakers, atrás apenas de smartphones/tablets, com $28 \%$, e rádio AM/FM, com $20 \%$ - os dados de tablets foram agregados aos de telefones, pois o tablet está rapidamente caindo em desuso como dispositivo no mercado norte-americano, perdendo terreno para smartphones com telas grandes (de cinco polegadas para cima). A pesquisa TechSurvey 2018, conduzida pela Jacobs Media, indica um crescimento de $10 \%$ no consumo de smart speakers entre 2017 e 2018, chegando a $21 \%$ dos entrevistados.

Ainda segundo The Smart Audio Report, os novos gadgets estão sendo usados regularmente para ouvir música $(68 \%)$, para saber a previsão do tempo $(58 \%)$, para perguntas em geral $(52 \%)$, para ouvir notícias (45\%) e como despertador/alarme e hora certa (43\%). A lista inclui ainda a escuta de música em rádio AM/FM (38\%), programas informativos e de variedades de emissoras AM/FM (32\%), programas esportivos em rádio AM/FM (22\%) e podcasts (17\%).

Entre as principais razões para desejar um alto-falante inteligente, estão a possibilidade de escutar música (90\%) e notícias e informação (77\%), o que explicita a concorrência direta com o rádio hertziano em torno da atenção da audiência.

Há evidências de que a relação afetiva que a Amazon buscou construir, em suas campanhas de marketing, entre a assistente de voz Alexa e o público deu frutos. Dados da pesquisa The Infinite Dial expõem que:

- $42 \%$ dos donos de smart speakers afirmam que o aparelho é essencial para suas vidas cotidianas;

- $57 \%$ já compraram algum produto através do aparelho; 
- $70 \%$ afirmam estar ouvindo mais áudio;

- $\quad 28 \%$ passaram a assinar serviços de streaming;

- $\quad 65 \%$ não querem nem pensar em voltar à vida sem um desses gadgets,

- $61 \%$ concordam que ter um smart speaker é como ter alguém com quem conversar (grifo nosso).

Líder de mercado, a Amazon soube capitalizar a audiência de seu recém-lançado serviço de streaming, o Amazon Music, que cresceu 50\% em um ano e ao fim de 2017 já respondia por $9 \%$ da audiência de rádio on-line nos Estados Unidos, encostando em rivais estabelecidos como Apple Music (10\%) e iHeartRadio (11\%) e atrás apenas dos líderes Pandora (31\%) e Spotify (20\%).

Em média, quem tem um smart speaker ouve mais de quatro horas de música por semana no aparelho e gasta mais de uma hora ouvindo notícias e outra hora ouvindo podcasts. Em tese, esse aumento do consumo beneficiaria as emissoras de rádio tradicionais, mas há muitas interrogações em relação ao papel que estas poderão desempenhar no novo ecossistema midiático.

Para Pedrero Esteban (2018), as rádios têm que se unir para capitalizar o potencial de um dispositivo de base sonora, através de campanhas institucionais que associem a radiofonia à nova tecnologia e afirmem sua credibilidade, reconhecendo os serviços de streaming e podcasting como seus principais concorrentes. Para o pesquisador espanhol, é preciso enfrentar desafios quanto à experiência de uso e à oferta de conteúdos. Diante de uma interface de voz, questiona, como saber o que está disponível para escuta? E será que as emissoras em ondas hertzianas serão capazes de oferecer conteúdos diferenciados daqueles veiculados em antena?

Esses desafios estão sendo enfrentados nesse exato instante pelos principais atores do mercado de radiodifusão. Tradicionais veículos de comunicação estão sendo obrigados a selar acordos comerciais com os fabricantes de smart speakers para que seus conteúdos estejam disponíveis nos aparelhos. Nesse processo, têm de se sujeitar aos termos de uso de plataformas proprietárias de gigantes como Amazon, Google e Apple, ajudando a gerar um enorme tráfego nas suas redes e possibilitando a mineração de dados preciosos sobre hábitos de consumo. E não há qualquer garantia de que os produtores de conteúdos tenham acesso a estas informações, que têm claro interesse comercial e estratégico, nem que tenham visibilidade para o consumidor entre as opções de customização.

Neste cenário, como ficarão as rádios locais? Quais as garantias de que teremos uma oferta diversificada de conteúdos através de smart speakers, e não um afunilamento, com o consumo dirigido a parceiros comerciais dos fabricantes?

\section{Novos conteúdos para os grandes atores}

O Brasil é um grande mercado para a produção de conteúdo sonoro. Com tradição no consumo de rádio, o país hoje apresenta altos índices de consumo de áudio - tanto em plataformas digitais quanto fora delas. Segundo a pesquisa TIC Domicílios divulgada pelo Centro de Estudos para o Desenvolvimento da Sociedade da Informação (Cetic.br) em 2018, 71\% dos internautas brasileiros tinham hábito de consumir áudio (Consumo de..., 2018). Os smart speakers, no entanto, são atores recentes nesse terreno de disputas. 
Enquanto Alexa, até o início de 2019, ainda não falava português e formalmente não integrava a ecologia de mídia brasileira, o assistente de voz da Google ia ganhando espaço tanto nas casas quanto nos telefones móveis. Para o mercado brasileiro existem hoje seis serviços informativos disponíveis para serem consumidos através do Google Home ou do Google Assistant. Deles, quatro são produzidos por emissoras de rádio (Central Brasileira de Notícias, a CBN - maior rede All News do país, pertencente ao Sistema Globo de Rádio -, Jovem Pan, Litoral FM e Gaúcha) e dois pelas redações de mídia impressa ou digital (revista Veja e jornal $O$ Estado de S. Paulo). Neste artigo olhamos especificamente para as emissoras de rádio, embora em uma escuta exploratória realizada durante uma semana em fevereiro de 2019 tenham sido identificadas a estrutura de síntese noticiosa em todos os áudios e a manutenção da identidade acústica da programação nas produções das emissoras radiofônicas.

Importante lembrar que o Google Home tem investido mais no mercado brasileiro e é o assistente de voz em que estão presentes os meios brasileiros, mas ainda assim não apresenta, em sua página, o português como língua oficial (Talk to..., 2019). Ainda assim, no país é possível acessar conteúdos, interagir com a assistente de voz e acionar dispositivos de smart home em português desde 2018 (Veja como..., 2019). Entre os desafios apresentados pelo avanço dos assistentes de voz no mercado estão a oferta de novos conteúdos e o modelo de negócio. No primeiro caso, as possibilidades começam a ser exploradas. Para 0 executivo-chefe da Gushup, parceira da Google no desenvolvimento do Google Assistant, Beerud Sheth...

Com alto-falantes inteligentes baseados em voz e seus assistentes de Inteligência Artificial, os publicadores de conteúdo podem ser uma presença ambiental através do meio ambiente de seus usuários, e os robôs inteligentes que eles criam podem também personalizar notícias para o usuário entregando-Ihe apenas conteúdo específico. ${ }^{7}$

As possibilidades se expandem no jornalismo e na ficção. Grandes empresas de comunicação como The Guardian, BuzzFeed e NBC já investem em produções especiais para os alto-falantes inteligentes. No rádio, a rede pública norte-americana NPR está presente nos principais dispositivos - Amazon Echo, Google Home, Apple HomePod, Microsoft Cortana, Samsung Bixby. As produções variam de transmissão direta da programação a acesso a programas ou podcasts específicos - sejam eles produções para antena ou exclusivas para plataformas digitais.

O conteúdo tem se revelado o foco das gigantes que comandam o segmento. Amazon e Google, principalmente, ampliam seu público e a relação emocional construída com ele através da voz. Um exemplo é a adaptação de conteúdo e compreensão de voz lançada pela Amazon em abril de 2018, que agora "responde melhor" a questões feitas por crianças, como "Alexa, quem é Harry Potter?" - a inteligência artificial compreende melhor a fala infantil, respondendo, por exemplo, a comandos como "Awexa". A interface foi definida pela pesquisadora da Carnegie Mellon University Justine Cassell como "Mary Poppins da tecnologia" por seu apelo ao público infantil (Kids, Meet..., 2018). É a exploração do que Cicció e Quesada (2018) definem como a base da tecnologia de comando por voz: a naturalidade e a simplicidade levando a

\footnotetext{
${ }^{7}$ No original: "With voice-based smart speakers and their AI assistants, content publishers can be an ambient presence throughout their user's environment, and the smart bots they create can also personalize news for the user - delivering only specified content to them".
} 
uma interação intuitiva e cotidiana com o usuário. Diferente do que previa Weisenbaum, não se trata de uma relação de desabafo, lembrando um diálogo com o terapeuta - embora o dispositivo da Amazon, por exemplo, reaja a comandos como: "Alexa, I'm bored" ("Alexa, estou entediado"), oferecendo atividades personalizadas ao padrão de consumo do sujeito que fala -, mas de comandos simples para acionamento de aplicativos. A complexificação da experiência se dá no interior das narrativas propostas pelos aplicativos e pelo potencial imersivo dos conteúdos ofertados, mas sempre conduzidos a partir de comandos intuitivos e aparentemente naturais.

Esta pretensa naturalidade tem levado à conversão dos smart speakers - a exemplo do que ocorreu com o rádio - em um sujeito das relações domésticas. O assistente de voz é visto por usuários como alguém com quem conversar, que auxilia na resolução de problemas e nas atividades cotidianas. De acordo com a pesquisa de Druga et al. (2017), a aproximação com crianças é intensa e efetiva, já que elas veem no dispositivo um grande nível de confiabilidade e buscam, entre outras coisas, saber "quem é" Alexa.

Crianças menores tentam entender os agentes como pessoas, "[Alexa,] qual sua cor favorita?", "Ei, Alexa, quantos anos você tem?". Crianças mais velhas testam o que o agente faria quando lhe pedem que realize ações humanas, como "você pode abrir portas?", "[Cozmo $\left.{ }^{8}\right]$ você pode pular?". Eles também perguntam como os agentes trabalham ("você tem um telefone dentro de você?") e como eles se definem ("O que você é?"). Crianças usam o gênero de forma intercambiável quando falam sobre os agentes. Gary e Larry se referiram a Cozmo como "ele" ou "ela" indistintamente. Gary: "Eu realmente não sei qual dos dois isto é". Larry: "É um menino... talvez por causa do nome, mas ainda sim você pode usar um nome de menino para uma garota e o de uma garota para um menino" (Druga et al, 2017, p. 4) ${ }^{9}$

Esta naturalização dos assistentes de voz como pessoas ou coisas próximas se deve aos usos implicados nos dispositivos. O diálogo de voz, segundo os autores, é uma variável fundamental para o estabelecimento desta relação. Outra variável apontada no estudo com crianças é a possibilidade de interação em movimento, em paralelo a brincadeiras e outras ações, sem deslocar o sujeito de suas atividades cotidianas - o que também remete a uma das características essenciais do rádio. Seriam os smart speakers, então, agentes em um possível movimento de rejuvenescimento da audiência em rádio expandido? Em paralelo ao movimento de ampliação do conteúdo infantil em emissoras de rádio e podcasts, a oferta de conteúdo para públicos específicos nos assistentes de voz gera um cenário propício para isso.

Grandes grupos têm inserido os smart speakers como protagonistas de seus modelos de negócios através dos games sonoros imersivos. Como parte da promoção do filme Jurassic World, a Universal lançou, em

\footnotetext{
${ }^{8}$ Pequeno robô fabricado pela Anki e dotado de inteligência artificial e suporte para assistente de voz, foi o brinquedo mais vendido nos EUA em 2017. Disponível em: https://www.anki.com/en-us/compant/press. Última consulta: 5/7/2018.

${ }^{9}$ No original: "Younger children tried to understand the agents like a person, '[Alexa], what is your favorite color', 'Hey Alexa, how old are you'. Older children tested what the agent would do when asked to perform actions that humans do, 'Can you open doors?' '[Cozmo] can you jump?'. They also asked the agents how they worked ('Do you have a phone inside you?') and how they defined themselves ('What are you?'). The children used gender interchangeably when talking about the agents. Gary and Larry referred to Cozmo as both "he" and "she". "I don't really know which one it is" - Gary. "It's a boy...maybe because of the name but then again you could use a boy name for a girl and and girl name for a boy" - Larry."
} 
junho de 2018, o jogo interativo Jurassic Park Revealed. No jogo, o usuário visita o parque com um guia e precisa tomar decisões sobre o que fazer, quais objetos levar ou deixar, interagindo com o cenário (acústico e visual) do filme. A Universal não foi a primeira empresa a desenvolver games para smart speakers integrados a outras produções ou como peças de divulgação. A HBO lançou recentemente Westworld: The Maze, que explora a relação e o conhecimento do fã com a série de TV Westworld. O jogo fala diretamente para o fandom, já que o avanço nas fases só acontece através da resposta correta a questões sobre a série (Martin, 2018).

Apropriando-se de estratégias narrativas dos já tradicionais audiogames, os jogos desenvolvidos para os assistentes de voz potencializam a imersividade do consumo e convertem o ambiente físico da casa em um espaço de interação com a história. A estrutura narrativa, lembram Cicció e Quesada (2018), se assemelha às dos jogos de tela, com um argumento claro e módulos de progressão do usuário conduzidos pela narrativa acústica - seja através do potencial imersivo da ambientação, seja pela constituição de personagens ou uso de locuções. Há também, principalmente nos audiogames de smart speakers, a adoção da tecnologia de reconhecimento de voz para a ampliação do caráter personalizável da experiência imersiva.

Os modelos de negócio tradicionais também têm espaço no conteúdo de assistentes de voz. De acordo com Ju et al. (2017), os anúncios publicitários apresentados nestes dispositivos têm caráter interativo e se mesclam aos conteúdos informativo e utilitário. Associados ao padrão de consumo do usuário coletado a partir de seu histórico ou de palavras-chave apresentadas por ele, sugerem, por exemplo, bilhetes de peças teatrais citadas durante o consumo de música através do smart speaker. Como o dispositivo é integrado a redes de compras, é possível adquirir o bilhete via Amazon Echo ou interromper a transmissão do anúncio em seu primeiro diálogo. Segundo os autores, ainda não é possível medir o impacto dos anúncios, mas esta seria uma reinterpretação do modelo de negócio tradicional da publicidade.

O crescimento da oferta de conteúdo nos assistentes de voz não tem levado, pelo menos nas emissoras de rádio do Brasil, à criação de novos produtos sonoros. A apuração do conteúdo tende a ser aproveitada das redações. No caso do Grupo Rede Brasil Sul de Comunicação (RBS), de Porto Alegre, as manchetes do portal GaúchaZH (que une conteúdos do jornal Zero Hora e da Rádio Gaúcha) são lidas por um dos principais comunicadores da emissora, Daniel Scola. Ainda que a gravação seja realizada exclusivamente para os smart speakers, não se trata de desenvolvimento de novos produtos, pelo menos neste primeiro momento, já que a emissora iniciou suas transmissões via Google Home e Google Assistant em fevereiro de 2019. Outras emissoras entraram neste nicho de mercado antes. É o caso da Jovem Pan, da Litoral FM e da CBN.

No trabalho de campo realizado para esta pesquisa, foram realizadas entrevistas com os responsáveis pela implementação das ações de duas emissoras no Google Home ${ }^{10}$ : Carlos Eduardo Dutra, Gerente de Projetos com Tecnologia Inovadora utilizando Metodologias Ágeis (SCRUM) da Rede Gazeta, à qual pertence a Rádio Litoral FM; e Thiago Barbosa, gerente de Jornalismo da CBN, pertencente ao Sistema Globo de Rádio. As duas emissoras veem os smart speakers como parte do futuro do rádio, no entanto, os olhares para este novo fenômeno são distintos.

O Sistema Globo de Rádio aposta no dispositivo como um espaço para ampliação da audiência do meio e para conhecimento futuro mais detalhado de seu público. Já possui algum conhecimento sobre o perfil do seu ouvinte de podcasts, que é "mais jovem, mais escolarizado e com renda um pouco mais alta do que a

${ }^{10}$ Não foram identificados aplicativos desenvolvidos por emissoras de rádio brasileiras para o Amazon Echo, PodHome ou para o recém anunciado Galaxy Home. 
média dos ouvintes em FM" (Barbosa, 2019). A preocupação com este conhecimento do público e com a busca pelos dados gerados pela audiência e que caracterizam seus hábitos de escuta dialoga com este rádio no contexto de big data e com o necessário reposicionamento das emissoras em relação às mudanças na ecologia de mídia. A CBN aposta na integração como estratégia de difusão do conteúdo. Hoje, como explica Thiago Barbosa (2019), o boletim em forma de podcast "Panorama CBN é editado somente para as plataformas digitais, inclusive uma das ferramentas do Google, mas também para outras plataformas". As atualizações ocorrem de segunda a sexta, por volta das 19h. Na percepção de Barbosa, os smart speakers, até o momento, no Brasil, vêm desempenhando papel secundário, apesar de seu enorme potencial. Isso porque os ouvintes acessam conteúdos através de assistentes de voz mais pelo telefone móvel. Sintonizado nos mercados do dispositivo em inglês e alemão, o gerente da CBN acredita, no entanto, que os smart speakers "não são como o Google Glass e vão conquistar as pessoas". Já a Rede Gazeta aposta no protagonismo do áudio para além das emissoras de rádio.

Entendemos que entre 5 a 10 anos o consumo de notícias em diferentes plataformas será exclusivamente via voz, não existindo mais teclado nos dispositivos digitais. Por isso, hoje estamos desenvolvendo todos os nossos produtos digitais para serem consumidos via voz. Inclusive estamos com um site de notícias que poderá ser consumido totalmente por comandos de voz. (Dutra, 2019)

Para isso, o trabalho tem sido desenvolvido em colaboração com a área de Tecnologia da Informação. Segundo Dutra (2019), a Litoral FM tem no Google seu único parceiro, devido à capacidade e agilidade no desenvolvimento de tecnologias inovadoras. A Rede Gazeta não possui uma caracterização prévia de sua audiência, mas investe nas métricas como uma das prioridades para as fases futuras do projeto. A atualização não é diária, mas varia de duas a quatro vezes por semana e, segundo ele, conta com a qualificação de desenvolvimento de conteúdos em áudio da Litoral FM para criar peças exclusivas.

Assim como na CBN, observamos que a produção de conteúdo sonoro para os smart speakers afeta as rotinas da redação, mas não abre, pelo menos neste momento, novos postos de trabalho. Tanto Thiago Barbosa (2019) quanto Carlos Dutra (2019) indicaram não ter havido contratações para alimentar a ferramenta do Google.

\section{Considerações finais}

A experiência coletiva da audiência de rádio e TV, típica no século XX, vai rapidamente se reconfigurando. O consumo de mídia sob demanda em dispositivos como os smart speakers, ao mesmo tempo que traz impulso inédito à comunicação sonora, pulveriza o público, trazendo uma série de desafios políticos, sociais e culturais.

O contexto de big data em que o consumo midiático se dá torna o cenário ainda mais complexo, acentuando o declínio de empresas tradicionais de comunicação, até aqui incapazes de capitalizar o potencial de geração de dados sobre suas audiências. 
Num ambiente midiático em que empresas monitoram o uso que fazemos do cartão de crédito, das redes sociais on-line, dos serviços gratuitos de email e buscas, entre outras atividades, causa surpresa que o big data praticamente não seja usado para balizar oferta de conteúdos das tradicionais empresas de comunicação, nem para rentabilizar a audiência, através da customização da oferta de produtos e serviços. Ocorre nos últimos anos um profundo processo de reintermediação (Bustamante et al., 2003, p. 333-335) da mídia sonora, em que surgem oportunidades para pequenas e médias empresas inovadoras, mas também se fortalecem novos (e já poderosos) intermediários, no caso notadamente Amazon e Google, entre outras empresas que anunciaram investimentos no mercado de smart speakers. Com a escuta através destes dispositivos, a radiodifusão agrava sua dependência de métricas de audiência que não lhe são transparentes em absoluto. Situação particularmente preocupante num momento em que a publicidade migra cada vez mais para as plataformas digitais.

Este cenário em que o big data se torna um ativo cada vez mais cobiçado coloca uma série de desafios também para a pesquisa em comunicação. O grande problema passa a ser a desigualdade no acesso ao big data desestruturado que trafega nas transações comerciais, bem como aquele relativo às atividades cotidianas, incluindo o consumo midiático. A comunicação precisa, cada vez mais, levar em consideração os dados potencialmente gerados pelo tráfego nas redes on-line, buscando estratégias de mineração. Há aplicativos específicos para compilação de dados relativos a postagens no Twitter, por exemplo, mas sites de relacionamento têm estruturas de TI que tornam o tráfego absolutamente opaco aos olhos do pesquisador. O mesmo parece acontecer em relação aos assistentes de voz.

Precisamos de novas perspectivas para dar conta de um objeto extremamente complexo, sobre o qual pairam interesses bilionários e onde se constitui uma nova arena política e econômica. Teremos que desenvolver, nos próximos anos, novos instrumentos de pesquisa que possibilitem o monitoramento em tempo de real de hábitos de consumo de mídia. Para isso, será preciso trabalhar em parceria, numa lógica distribuída e colaborativa, com pesquisadores de ciências da computação. Temos que avançar em relação aos aparatos de medição de audiência já existentes.

A mudança não precisa ser apenas de base tecnológica. Deve também levar em conta a orientação epistemológica, numa interface entre as ciências sociais aplicadas e o vasto campo de estudos do big data, empregando instrumentos multimétodo. Precisamos reconstruir nossa metodologia de pesquisa para conjugar ferramentas qualitativas e quantitativas, pensando em corpora que abrangem agora a totalidade do universo pesquisado, e não mais apenas amostras estatísticas ou seleções qualitativas de escopo limitado. Algumas destas mudanças já se iniciaram, ainda que centralizadas nas mãos dos grandes atores da cadeia produtiva da comunicação. Ações integradas e iniciativas que apontam para uma transmídia radiofônica (Lopez et al., 2018; Lopez e Viana, 2017) indicam os campos da narrativa e do conteúdo como possíveis caminhos de inovação e exploração dos assistentes de voz pelo rádio expandido. Além da integração às emissoras em seus conteúdos hertziano e digital, os smart speakers se revelam como um espaço de potencialização do diálogo, da proximidade e da personalização do meio, fortalecendo a relação com o público e suas práticas cotidianas. Neste sentido, revela-se aqui um desafio para o debate sobre o modelo de negócio do rádio, integrando novas possibilidades e dinâmicas de financiamento - ao menos para emissoras mais bem estruturadas e com fôlego para investir em tecnologia e em inovação de formatos e linguagens. 
Neste momento inicial da implementação, ainda não observamos inovações na narrativa acústica construída ou a integração multiplataforma do conteúdo de maneira complexa. No entanto, as entrevistas realizadas revelaram a busca pelo investimento e pela compreensão da tecnologia, pensando em possíveis aplicações tanto para a expansão e para o conhecimento da audiência quanto para a (re)criação. ampliação e inovação de conteúdos em áudio.

O protagonismo do áudio no futuro da comunicação, indicado por um dos entrevistados, nos leva também a pensar no redimensionamento do seu papel, seja a partir de sua inserção em atividades cotidianas quanto da apropriação de elementos externos à comunicação sonora ou radiofônica, como a organização de agenda, de listas de compras e afazeres, as mudanças no consumo de música e em seu compartilhamento, a compreensão deste consumo como uma prática não mais individual, mas que volta a invadir o espaço doméstico integrando a família, embora também respeite e incentive as individualidades, já que cada sujeito pode ter seu perfil no próprio smart speaker, acionando ações ou skills previamente conectados.

As mudanças refletem-se diretamente no consumo de rádio, de áudio e de música. Mas precisam ser consideradas também nas rotinas das emissoras, no desenvolvimento de novas habilidades, na integração ao cotidiano dos ouvintes e nas pistas digitais que deixam, revelando práticas coletivas e tendências através dos dados coletados pelos sistemas. Caso contrário, novos e poderosos intermediários virão assumir as lacunas deixadas, como mostram os dados de crescimento do serviço de streaming Amazon Music nos EUA. Assim como as emissoras, a academia não pode vir a reboque de discussões sobre as mudanças estruturais no mercado de mídia sonora, mudanças que têm potencial de reduzir ainda mais a diversidade de vozes a que temos acesso. É preciso colocar na mesa de debates normas regulatórias que assegurem acesso da população à informação de múltiplas fontes, e não apenas daquelas que fecharem acordos comerciais para estarem presentes em posição de destaque nos smart speakers. Corremos hoje o risco de termos nossos horizontes limitados se não houver garantias legais de acesso a conteúdos diversificados e qualificados, de múltiplas fontes de informação. Hoje, num mercado ainda absolutamente à margem de qualquer regulação, quem controla o que vamos ouvir quando perguntarmos a Alexa - ou qualquer outro assistente de voz quais são as notícias ou simplesmente pedirmos para ligar o rádio?

\section{Referências}

Anderson, C. W., Bell, Emily e Shirky, Clay (2013). Jornalismo pós-industrial: adaptando-se ao presente. Revista de jornalismo, 5.

Bentley, F., et al. (2018). Understanding the long-term use of smart speaker assistants. Proc acm interact. Mob. Wearable ubiquitous technol. 2-3, article 91. Https://doi.org/10.1145/3264901.

Bustamante, Enrique (org.) (2003). Hacia un nuevo sistema mundial de comunicación: las industrias culturales en la era digital. Barcelona: Gedisa.

Cicció, José Antonio; Quesada, Luis (2018). Framework for creating audio games for intelligent personal assistants. In: Ahram, T.; Falcão, C. (ed.). Advances in human factors in wearable technologies and game design, advances in intelligent systems and computing 608. Basel: Springer.

Coddington, M. (2015). Clarifying journalism's quantitative turn: a typology for evaluating data journalism, computational journalism, and computer-assisted reporting. Digital journalism, 3(3), 331-348. 
Agência brasil, 25/07/2018. Consumo de vídeo online já é preferido por $71 \%$ dos internautas do país. Disponivel em: http://agenciabrasil.ebc.com.br/geral/noticia/2018-07/consumo-de-video-onlineja-e-preferido-por-71-dos-internautas-do-pais. Última consulta: 08/03/2019

De Marchi, L. (2016). A destruição criadora da indústria fonográfica brasileira, 1999-2009: dos discos físicos ao comércio digital de música. Rio de janeiro: Folio Digital.

Druga, S.; Williams, R.; Breazal, C.; Resnick, M. (2017). "hey google is it ok if i eat you?" Initial explorations in child-agent interaction. Retrieved from: https://www.media.mit.edu/publications/hey-google-isit-ok-if-i-eat-you-initial-explorations-in-child-agent-interaction/. Última consulta: 5/7/2018.

Edison research (2018). The infinite dial. Retrieved from: http://www.edisonresearch.com/infinite-dial2018/. Última consulta: 22/6/2018.

Gandomi, A.; Haider, M. (2015). Beyond the hype: big data concepts, methods, and analytics. International journal of information management, 35, 137-144.

Giantomaso, I. (2018). Amazon echo: relembre três casos polêmicos envolvendo a alexa. Techtudo. Retrieved from: https://www.techtudo.com.br/listas/2018/05/amazon-echo-relembre-tres-casospolemicos-envolvendo-a-alexa.ghtml.

Greenberg, A. (2017). A hacker turned an amazon echo into a 'wiretrap'. Wired. Retrieved from: https://www.wired.com/story/amazon-echo-wiretap-hack/. Última consulta: 10/7/2018.

Ju, J.; Kim, D.; Park, K.; Park, Y.; Yun, J.; Ahn, J. (2017). Is advertising on an ai speaker effective? The role of interactivity, product type, and thematic congruence. Icit 2017 proceedings of the 2017 international conference on information technolog y. Singapura, 27-29 dez.

Kischinhevsky, M. (2016). Rádio e mídias sociais - mediações e interações radiofônicas em plataformas digitais de comunicação. Rio de janeiro: Ed. Mauad $x$.

Kischinhevsky, M., de Marchi, L. (2016). Expanded radio. Rearrangements in brazilian audio media markets. Radio, sound \& society journal, 1, 75-89.

Kischinhevsky, M., Vicente, E., de Marchi, L. (2015). Em busca da música infinita: os serviços de streaming e os conflitos de interesse no mercado de conteúdos digitais. Revista fronteiras, 17, 302-311.

Lee, Dave (2018). Como alexa, a assistente virtual da amazon, gravou e compartilhou conversa privada de casal. $B B C, 29 / 5 / 2018$. Retrieved from: https://www.bbc.com/portuguese/geral-44280917.

Lewis; Seth C. (2015). Journalism in an era of big data. Digital journalism, 3(3), 321-330.

Lopez, D.C.; Freire, M. (2018). Métodos digitais aplicados às pesquisas de rádio expandido: desafios metodológicos. Anais do $41^{\circ}$ congresso brasileiro de ciências da comunicação, Joinville.

Lopez, D.C.; Viana, L.; Avelar, K. (2018). Imersividade como estratégia narrativa em podcasts investigativos: pistas para um radiojornalismo transmídia em in the dark. Anais do 270 encontro nacional da compós, Belo Horizonte.

Lopez, D.C.; Viana, L. (2016). Construção de narrativas transmídia radiofônicas: aproximações ao debate. Mídia e cotidiano, 10, 158-173.

Martin, C. (2018). Smart speakers tapped for interactive "jurassic world" adventure. Media post. Retrieved from: $\quad$ https://www.mediapost.com/publications/article/321152/smart-speakers-tapped-forinteractive-jurassic-wo.html.

Martins, S. (2017). "alexa, qual é a temperatura hoje?". Instituto de tecnologia e sociedade do rio. Retrieved from: https://feed.itsrio.orq/alexa-qual-é-a-temperatura-hoje-f9ba0ed0188f. 
Noda, K. (2017). Google home: smart speaker as environmental control unit. Disability and rehabilitation: assistive technology, 13(7):674-675.

Park, K., Kwak, C., Lee, J., Ahn, J-H. (2018). The effect of platform characteristics on the adoption of smart speakers: empirical evidence in south korea. Telematics and Informatics, 35(8), 2118-2132.

Rogers, E. (1983). Diffusion of innovations. 3a. New York: The Free Press.

Smith, B. (2017). Ok, google: designing information architecture for smart speakers. Programa de pósgraduação em arquitetura da informação (dissertação de mestrado). Aalborg University: Aalborg.

Vicente, E., Kischinhevsky, M., de Marchi, L. (2018). A consolidação dos serviços de streaming e os desafios à diversidade musical no brasil. Eptic on-line (ufs), 20, 25-42.

Ziegler, L. D. (2016). Radio as numbers: counting listeners in a big data world. Journal of radio \& audio media, 23(1), 182-185. 